\title{
RENOVACIÓN URBANA, HERENCIA INDUSTRIAL Y TURISMO: UN PROCESO CON ELEMENTOS DE ÉXITO EN AVILÉS (ASTURIAS) ${ }^{1}$
}

\author{
Paz Benito del Pozo \\ Departamento de Geografía y Geología. Universidad de León \\ paz.benito@unileon.es
}

\section{RESUMEN}

Este trabajo analiza la transformación funcional y paisajística de Avilés a partir de la crisis y desmantelamiento de su empresa más emblemática y poderosa, Ensidesa, la primera fábrica siderúrgica integral de España y puntal de la política industrial franquista. Se trata de demostrar que el legado de la desindustrialización, bien gestionado, puede generar recursos alternativos que actúan como factores de impulso urbano y soporte de funciones nuevas para la ciudad, capaz de proyectar una imagen renovada y coherente con su pasado industrial. El resultado de esta estrategia de política urbana en Avilés apunta hacia un modelo de éxito, no exento de luces y sombras, que tiene en el turismo urbano la actividad más elocuente de la transformación llevada a cabo desde comienzos de los años 2000, y en el paisajes industrial un recurso turístico nada desdeñable cuando se vincula a la cultura industrial y a un pasado que se interpreta en clave de memoria y patrimonio.

Palabras clave: renovación urbana, ciudad industrial, herencia industrial, turismo urbano, Avilés, Asturias.

Fecha de recepción: diciembre 2014.

Fecha de aceptación: septiembre 2015.

1 Este trabajo forma parte de los resultados del Proyecto de Investigación I+D de Excelencia, Ministerio de Economía y Competitividad, Subprograma de Generación de Conocimiento, convocatoria 2013. Referencia CSO2013-447205-P 


\section{ABSTRACT}

This paper analyzes the functional and landscape transformation Aviles from the crisis and dismantling of its most iconic and powerful company, Ensidesa, the first integrated steel mill strut Spain and Franco's industrial policy. It is shown that the legacy of deindustrialization, well managed, can generate alternative resources that act as factors of urban momentum and support new functions for the city, which is capable of projecting a new and coherent image with its industrial past. The result of this strategy of public officials points to a model of success, not without its lights and shadows, which is in the most eloquent urban tourism activity planning and production patterns, since years 2000, as well as the potential for driving the industrial landscapes, a new product-claim negligible in the context of cities with a past that is interpreted in key memory and heritage.

Keywords: urban renewal, industrial city, industrial heritage, urban tourism, Avilés.

\section{INTRODUCCIÓN}

La ría de Avilés, situada en el Área Central de Asturias e integrada en el espacio metropolitano que definen las tres ciudades más importantes de la región, Oviedo, Gijón y Avilés, se industrializó a lo largo del siglo XIX y primera mitad del siglo XX según las pautas de primera revolución industrial. Un proceso tardío, de modesto alcance regional y con impactos territoriales focalizados en terrenos sin urbanizar cuya mayor ventaja era su localización portuaria. Sin embargo, la política económica del franquismo va a favorecer el desarrollo de un verdadero complejo industrial a partir de los años de 1950, con el resultado de una notable concentración en ambas márgenes de la ría de grandes empresas públicas y privadas dedicadas a actividades siderometalúrgicas y de industria pesada en general, que se suman al incipiente polo industrial que se había organizado en la etapa anterior en torno a la actividad de la Real Compañía Asturiana de Minas, pionera en la ría y con negocios mineros y metalúrgicos desde mediados del 1800. A esta empresa de capital belga seguirán Siasa, Endasa, Azsa, Cristalería Española o Mefasa, así como otras compañías de menor tamaño y entidad productiva que refuerzan el tejido industrial de la zona. La instalación de Ensidesa será el colofón de un proceso de industrialización que conlleva la transformación radical de la ría y de la propia villa de Avilés, que conoció un crecimiento demográfico explosivo y adquirió la morfología y las funciones propias de una ciudad-empresa según el patrón fordista (Erice, 1980; Morales, 1982; Ojeda, 1985; De la Madrid, 2008).

La base productiva de dicho complejo estaba en la fabricación de acero, aluminio, zinc, construcción naval y en los tráficos portuarios generados por esa misma industria. La evolución de los mercados internacionales y los cambios tecnológicos y de modelo productivo que afectaron a la industria española en el período 1980-1999 tuvieron una incidencia negativa en la industria avilesina (obsoleta y especializada en sectores maduros), que entró en fase de recesión y provocó un cuadro de desindustrialización con efectos similares a los que se aprecian en otras ciudades españolas y europeas, atrapadas todas en una espiral de declive territorial que se tratará de superar desde finales de los años noventa con políticas 
de diversificación productiva y de renovación urbana no siempre exitosas (López Trigal, Relea y Somoza, 2003; Rodríguez y Méndez, 2005; Méndez y Pascual, 2006; Gómez García, 2007; Juaristi, 2012; Sánchez y otros, 2012).

Asociada al declive industrial emerge la crisis urbana de Avilés, que se acompaña, entre otros fenómenos, de altas tasas de desempleo, descapitalización de la economía urbana, abandono de fábricas y talleres, degradación medioambiental y aparición de vacíos industriales, problemas a los que el planeamiento urbanístico y las estrategias de desarrollo urbano deberán dar respuesta, toda vez que las políticas de reindustrialización ensayadas desde mediados de los años ochenta y a lo largo de los noventa mostraron sus limitaciones para impulsar el crecimiento y crear oportunidades (Rodríguez y Busto, 2001; Leira y Calvo, 2003; Benito del Pozo, 2004; Sánchez y otros, 2012; Prada, 2014a).

En este trabajo se analizan la transformación funcional y paisajística de Avilés a partir de la crisis y desmantelamiento de su empresa más emblemática y poderosa, Ensidesa, la primera fábrica siderúrgica integral de España y un gigante que llegó a tener más de seis kilómetros lineales de instalaciones fabriles y dar empleo a 22.000 trabajadores, capaz de organizar la vida social y económica de Avilés y su comarca. En la actualidad, una parte de los terrenos liberados por Ensidesa dan soporte y contexto a nuevos usos que amplían la oferta de turismo cultural de Avilés, al tiempo que otorgan nuevo significado al paisaje industrial de la ría, en el que se mezclan elementos portuarios, fábricas viejas y naves rejuvenecidas, paseos y zonas verdes, avenidas industriales, instalaciones fabriles abandonadas y edificios de vanguardia que miran a la ciudad y al mar, componiendo un paisaje de gran potencial turístico. El interés aquí se centra en los elementos de ese nuevo paisaje y la influencia que pueden tener en la función turística que Avilés y su comarca tratan de reforzar haciendo hincapié en el legado industrial.

La metodología de análisis se basa en técnicas cualitativas, con especial importancia de la revisión bibliográfica para contextualizar el tema y justificar su oportunidad y enfoque, y el manejo de documentación urbanística obtenida mediante consultas realizadas en el Ayuntamiento de Avilés; también se ha recabado abundante información sobre estrategia y política urbano/comarcal, editada en forma de documentos de carácter divulgativo y/o técnico por el propio ente local. Esto se completa con entrevistas a informantes clave (concejal de Urbanismo y responsables de la Oficina de Turismo), en cuya compañía se han realizado varias visitas de reconocimiento del conjunto de la ría de Avilés, y con un exhaustivo trabajo de campo para obtener imágenes y observar los fenómenos más destacados relacionados con el proceso de transformación urbana que se analiza. Algunas técnicas cuantitativas básicas, como son el tratamiento de datos obtenidos de la agencia estadística regional Sadei y del propio Ayuntamiento avilesino, y la elaboración de tablas y gráficos permiten analizar en cifras el alcance del turismo y su impacto.

\section{LA IMPORTANCIA DEL LEGADO INDUSTRIAL EN LOS PROCESOS DE RENOVACIÓN URBANA}

Desde que la desindustrialización se impuso como fenómeno dominante en los territorios de tradición industrial y en las ciudades con mayor presencia de las grandes compañías, las viejas fábricas, naves, talleres y solares abandonados (lo que convenimos en llamar ruinas industriales), pasaron a convertirse a lo largo de los años de 1980 y 1990 en un problema gene- 
ralizado y extendido a todos los países europeos que fueron escenario de la Primera y Segunda Revolución Industrial. Por su magnitud y naturaleza, estas ruinas, que afectaban a varios cientos de miles de hectáreas, se perfilaron como un verdadero desafío territorial ya que para los solares y edificios abandonados por las empresas manufactureras, tanto grandes compañías como pequeños talleres, el mercado del suelo no garantizaba de forma espontánea su absorción y reutilización. Además, los suelos industriales improductivos, edificados o no constituían un riesgo medioambiental y un factor de degradación para las áreas urbanas, así como una fuente de gasto para las Administraciones públicas responsables (Capel, 1996; Álvarez, 2003 y 2007).

A fin de atajar estos problemas, en el seno de la Unión Europea se diseñó y activó un amplio repertorio de medidas económicas, urbanísticas y legislativas que permitieron desarrollar iniciativas de recuperación y puesta en valor de suelos y fábricas abandonadas para dotarlos de algún uso alternativo o bien para nuevas actividades productivas, que en el ámbito urbano servirán para dinamizar la economía de la ciudad y recualificar barrios empobrecidos y degradados a causa de la desindustrialización (Álvarez, 2008; Pardo Abad, 2008; Cañizares, 2010). La atención institucional al problema de las ruinas industriales se acompañó de una creciente sensibilidad social. Así muchos edificios, obras de ingeniería y paisajes en precario se han salvado de la extinción, el deterioro o la ruina gracias a merecer, no sin el esfuerzo de colectivos y asociaciones culturales y vecinales, la consideración de verdaderos monumentos. Y como tales, muchos de esos vestigios materiales de la herencia industrial se han protegido con la declaración de Bien de Interés Cultural o equivalente, figura regulada en España y otros países de su entorno por las leyes regionales de patrimonio, un instrumento que protege, conserva y favorece la recuperación de la herencia industrial, en particular de conjuntos fabriles y edificios industriales singulares que ocupan lugares centrales en la ciudad o su entorno, aunque también alcanza a espacios mineros y rurales. En el ámbito internacional hay conjuntos y paisajes industriales repartidos por todo el mundo declarados por la Unesco Patrimonio Mundial, entre ellos la conocida fábrica siderúrgica de Völklingen, en Alemania, fundada en el año 1873, cerrada en 1986 y reconocida como monumento mundial en 1994, lo que la convierte en la primera instalación o edificio industrial que se equipara, en términos culturales, a una catedral gótica, por ejemplo (http://portal.unesco.org/es/ev.php) (Pardo Abad, 2008; Hoehmann, 2008).

A escala urbana, las intervenciones que buscan poner en valor las viejas fábricas y recintos industriales heredados responden a iniciativas que están al servicio de una estrategia de largo alcance orientada a recualificar un barrio o un sector marginal de la ciudad, a crear nuevas centralidades o a generar focos de oportunidad allí donde la crisis de las actividades tradicionales se deja sentir con más fuerza. El edificio industrial (la fábrica, el almacén, el taller, incluso el poblado obrero) sirve para articular una estrategia de revitalización urbana que no se agota en la conservación, restauración o rehabilitación del inmueble sino que hay un proyecto de crear ciudad en torno a las industrias obsoletas y de conservar éstas como expresión de la memoria colectiva, como parte de la historia industrial, de la técnica y del trabajo del lugar. En este sentido, la vieja fábrica actúa a la vez como testimonio y como símbolo de una actividad que representó para la ciudad, en un pasado no lejano, el progreso y la abundancia, tal y como sugieren algunos autores (Capel, 1996).

Por último, las ciudades aprenden a lo largo del nuevo milenio a interpretar el patrimonio industrial como un recurso turístico, es decir, un elemento (edificio o paisaje) que se aplica 
a captar visitantes y reorganizar la estructura productiva de la ciudad en torno a una nueva actividad, el turismo, que a su vez tiene efectos sobre otras actividades consolidadas, las cuales deben adecuarse al nuevo reto (comercio, transporte público, hostelería). ¿Qué formas adopta el patrimonio industrial como recurso urbano al servicio del turismo? La herencia industrial se transforma en un museo, un centro cultural, un alojamiento singular o se aplica a ampliar los espacios de ocio o esparcimiento que atraen visitantes: parques temáticos, espacios deportivos, rutas y paseos entre ruinas industriales. En suma, a veces las viejas fábricas son meros contenedores con usos turísticos; o se convierten en museos de sí mismas para ofrecer al visitante una nueva visión de la industria que representan; en otros casos los terrenos industriales acogen nuevas actividades e instalaciones al servicio del turismo; y también están los espacios industriales que hablan de su pasado a través del paisaje, en forma de parques patrimoniales, ecomuseos o figuras similares (Álvarez, 2010).

Si ponemos el foco en las fábricas de hierro y acero y su relación con el turismo, Europa y América ofrecen ejemplos destacados ligados a las primeras etapas de la industrialización histórica de ambos continentes. Además de la citada fábrica musealizada de Volklingen (Alemania), en el este de Francia los hornos y baterías de coque de Uckange están protegidos y puestos en valor; en Ironbridge Gorge (Telford-Reino Unido) el pasado industrial es un eficaz reclamo turístico para el valle; las instalaciones de la factoría de Belvai en el sur de Luxemburgo forman parte de la oferta cultural del país; el ecomuseo de Seixal en Portugal incluye elementos siderúrgicos; en República Checa está el ejemplo de Vitkovice Iron Works, en Ostrava/Moravia; el Parque Fundidora en Monterrey, México, es otro caso expresivo de recurso turístico basado en el patrimonio siderúrgico; o el parque patrimonial Rivers of Steel, en Pittsburgh-Pensilvania, EE UU. En el norte de España el Museo de la Siderurgia y la Minería de Sabero (León) o el Museo de la Siderurgia de Langreo (Asturias) representan un modelo similar de intervención que busca captar turistas para zonas de escaso dinamismo económico y alejadas de los grandes circuitos (Hoehmann, 2008; Pardo Abad, 2008; Biel y Cueto, 2011).

De manera más específica, el debate sobre la transformación y patrimonialización de los espacios siderúrgicos sigue suscitando interés y aportando propuestas que apuntan a una estrategia de conservación e integración de las viejas instalaciones y paisajes del hierro y el acero en entornos urbanos renovados y con fuerte carga de cultural industrial, donde se piensa en clave de ciudadanía (paseos y bulevares temáticos, espacios de recreo y ocio que aprovechan las viejas fábricas) y en clave económica: atraer visitantes que refuercen la función turística. En tal sentido cabe destacar las aportaciones del Congreso Internacional organizado por la asociación Incuna en el año 2007 (vid. actas en http://incuna.es/jornadasincuna) y dedicado a las arquitecturas y territorios del hierro y el acero; y la Conferencia Internacional organizada en 2013 por la Universidad de Birmingham y el Ironbridge International Institute for Cultural Heritage (UK) sobre los paisajes y las culturas del hierro y el acero (vid. Universiy of Birmingham, 2013).

\section{DESMANTELAMIENTO INDUSTRIAL Y POLÍTICA URBANA: EL URBANISMO COMO MOTOR DE CAMBIO Y TRANSFORMACIÓN}

Cuando la ciudad debe afrontar el reto de dotar con nuevos usos y renovada funcionalidad un espacio industrial desmantelado (fábricas abandonadas, infraestructuras y terrenos indus- 
triales en desuso, poblados obreros, etc.) y con frecuencia cargado de historia y con un fuerte valor simbólico, puesto que acogió empresas y actividades que fueron fuente de riqueza y progreso para la sociedad, las soluciones se antojan complejas y requieren de un amplio debate y consenso social que se suele acompañar de la elaboración de planes estratégicos, la ejecución de planes especiales y la revisión del planeamiento urbano (Gómez García, 2007). Un desafío que con otras claves, pero equivalentes propósitos, afrontan las ciudades medias que se reinventan tras procesos de crisis y cambio y, en general, todas aquellas que precisan una redefinición de funciones y espacios, impelidas por la competitividad urbana y en el marco de procesos de resiliencia (Méndez, 2010 y 2012) -entendidos estos como «la capacidad que tiene un sistema para hacer frente positivamente a las condiciones adversas, simultaneamente a diferentes escalas (...) e involucrando a todos los componentes y agentes del sistema, gracias a la complementariedad de sus capacidades de absorción, adaptativa y transformadora» (López Trigal, 2015:534); o bien en contextos territoriales más complejos donde la calidad institucional es un factor decisivo (Manero y Molina, 2014).

En Avilés el mayor desafío empezó con las instalaciones obsoletas y terrenos infrautilizados de Ensidesa, que a principios de los años 2000 se desmantela parcialmente, tras un largo proceso de reconversión, privatizaciones y redimensionamiento de la compañía (en 1994 pasó a actuar como CSI-Corporación Siderúrgica; en 1997 se privatizó con el nombre de Aceralia; en 2001 se transformó en Arcelor y desde 2006 es parte de la compañía multinacional ArcelorMittal) (Cuesta Álvarez, 2006). Dicho desmantelamiento genera una bolsa de suelo libre de usos industriales de nada menos que 200 hectáreas de titularidad pública (propiedad de la Sociedad Estatal de Promociones Industriales, SEPI, heredera del Instituto Nacional de Industria), unos terrenos de alto valor estratégico para la ciudad y la ría, localizados en la margen izquierda, frente al casco urbano consolidado y sobre la dársena de San Agustín, con muelles de uso industrial fuera de servicio.

Según se desprende de la documentación municipal consultada (vid. Ayuntamiento de Avilés 2002a; 2002b y 2004) en Avilés la recuperación de las zonas industriales abandonadas fue desde 2002 un eje fundamental de la política municipal, que se plantea con un doble objetivo, dependiendo de la localización y características del suelo disponible: uno, recuperar para la ciudad y para usos ciudadanos los espacios (y edificios) más próximos y mejor situados a ambos lados de la ría y libres de presión industrial; y dos, habilitar nuevas áreas empresariales en las zonas adecuadas para ello. El objetivo es diversificar la base económica avilesina sin renunciar a la actividad industrial y poner en marcha un proceso de mejora urbana a todos los niveles: medioambiental, urbanístico, funcional y de imagen (marketing urbano). El punto de partida ofrecía un paisaje como el que se muestra en la figura 1, cuando Ensidesa estaba consolidada en la ría, pero ya empezaban los problemas de viabilidad de la compañía.

Existían antecedentes de intervención importantes. En efecto, en el año 1985 se reutilizaron los terrenos de la fábrica de SIASA (un proyecto franquista de los años de 1940 para fabricar chatarra sintética que se abandonó en 1968) con uso de polígono industrial en la margen izquierda de la ría, en un intento de los responsables políticos de que Avilés no perdiera peso industrial en el contexto local y regional. En el casco urbano la fábrica conocida como La Curtidora (1902, barrio de Versalles) fue rehabilitada y adaptada en su interior a usos de centro de empresas municipal, en marcha desde el año 1995 y consolidado como albergue de negocios además de ser un notable ejemplo de intervención en edificio indus- 


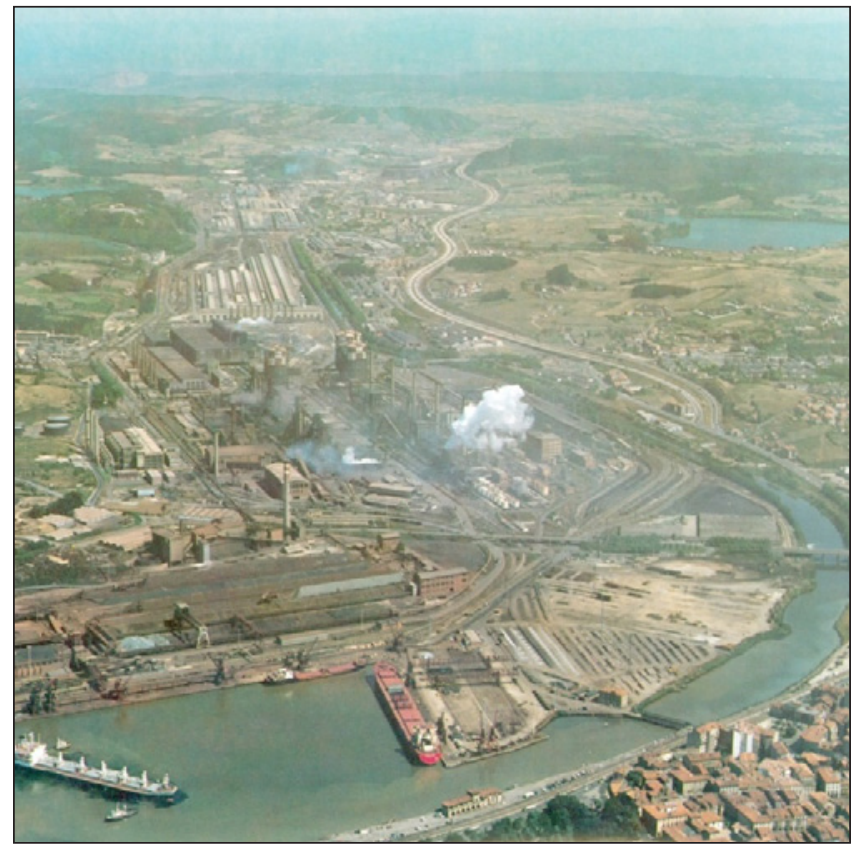

Fuente: Archivo de Ensidesa (sin fecha).

trial singular, lo que permite que hoy actúe como foco de interés turístico. También en zona urbana se recuperó a finales de los años 90 la fábrica de harinas de pescado El Águila (1893, calle del Ribero) como parte de los trabajos asignados a una escuela taller; restaurada respetando su valor arquitectónico, alberga hoy el Centro Municipal de Formación Ocupacional. Este edificio también figura en el circuito actual del patrimonio avilesino (Figura 2) (vid. Benito y Piñeira, 2014).

Figura 2

TERRENOS DE SIASA (A) Y EDIFICIOS DE LA CURTIDORA (B) Y EL ÁGUILA (C) DESTINADOS A USOS ALTERNATIVOS ENTRE LOS AÑOS DE 1980 Y 1990
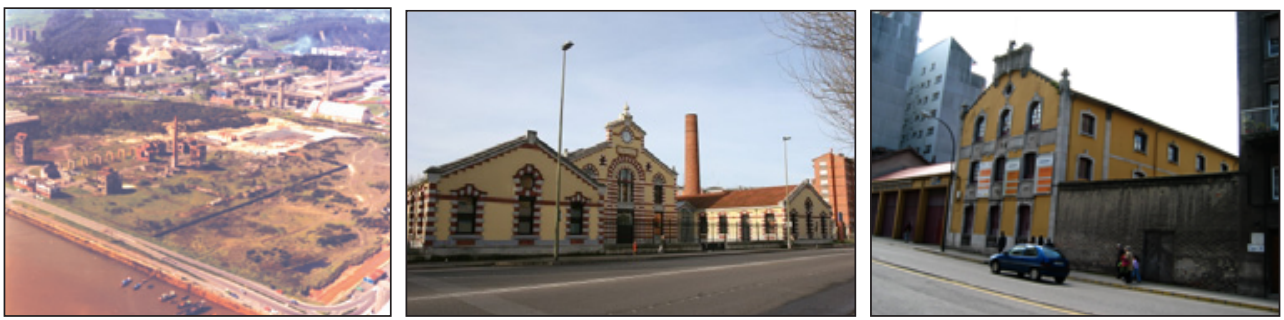

Fuente: Ayuntamiento de Avilés y foto de la autora (c). 
El Avance del Plan General de Ordenación Urbana 2002 contiene las líneas de intervención que orientarán la estrategia de recuperación de actividad económica y la regeneración urbana de Avilés y la ría (Benito del Pozo, 2004; Prada, 2014b) La acción prioritaria según este documento era acometer la renovación urbana sobre la idea de que Avilés podía ser una ciudad atractiva y competitiva más allá de su pasado siderúrgico, aunque sin renunciar a la cultura del trabajo industrial y a nuevas empresas ligadas al capital y el saber industrial acumulados. A tal efecto el Avance dirige el foco de interés hacia los siguientes elementos:

a) La ría: Calificada por el Plan como un espacio excepcional a recualificar. La ciudad puede integrar este brazo de mar y crecer sobre sus dos orillas, dando valor urbanístico a los frentes de agua y a los terrenos liberados por la industria y otros suelos degradados.

b) El puerto: Su pequeño tamaño y su especialización siderúrgica requieren una transformación. El puerto debe crecer y adquirir funciones no portuarias en el fondo de la ría, el más cercano a la ciudad y el más apto para actividades singulares: paseos urbanos y centro de congresos o similares.

c) Los suelos de la antigua Ensidesa: Es un recurso clave para la ciudad y su mayor oportunidad. Sirve como soporte para la extensión del área central de Avilés. Es aquí donde el Plan cifra su principal estrategia: crear un espacio multifuncional con usos industriales, terciario avanzado, equipamientos y usos residenciales.

d) El casco histórico: Un recurso que permite reforzar la función turística de Avilés y diversificar su economía.

e) La proximidad al aeropuerto: Representa una oportunidad para integrar la ciudad en el área metropolitana asturiana e incrementar sus relaciones a escala nacional.

En coherencia con esta propuesta, la principal operación urbanística se centró en la recuperación de los terrenos liberados por Ensidesa, los cuales conforman, ya se ha dicho, un solar de más de 200 hectáreas estratégicamente situado y con una óptima accesibilidad gracias a su conexión directa con el puerto avilesino y a su fácil acceso desde la autopista del Cantábrico (A-68). Las primeras tareas ejecutadas fueron la demolición de estructuras, seguida de la recuperación del suelo degradado, en lo que se invirtieron más de 21,5 millones de euros, para proceder después a la urbanización de los terrenos como parque industrial, el denominado Parque Empresarial Principado de Asturias, con un desarrollo por fases. Las obras de la primera fase del parque, inaugurado oficialmente en diciembre de 2002, tuvieron una duración de tres años y una inversión de 57,8 millones de euros. Con una extensión de 110 hectáreas brutas, tienen cabida en este renovado espacio empresarial los siguientes usos: zona para pequeñas y medianas empresas; zona para grandes industrias; 36 naves nido modulares y una zona de actividades logísticas en los terrenos contiguos a la ría.

La intervención descrita movilizó a numerosos agentes sociales y económicos y supuso la implicación de los tres niveles de la Administración: la entidad estatal propietaria del suelo, SEPI, el Principado de Asturias y el Ayuntamiento de Avilés. En la figura 3 se aprecia el impacto de esta intervención, que marca un antes y un después en el paisaje industrial de la ría y la recualifica en términos empresariales. Como testimonio de lo que fue la actividad siderúrgica en la zona se conserva la chimenea del antiguo Sínter, un elemento 
patrimonializado de valor simbólico y aún sin uso alternativo, delante del cual se ha erigido el Centro Tecnológico del Acero, actuación que sirve de corolario al parque empresarial.

Figura 3

EL CASCO URBANO DE AVILÉS Y LOS NUEVOS ELEMENTOS

QUE DEFINEN LA FUNCIONALIDAD Y EL PAISAJE DE LARIA

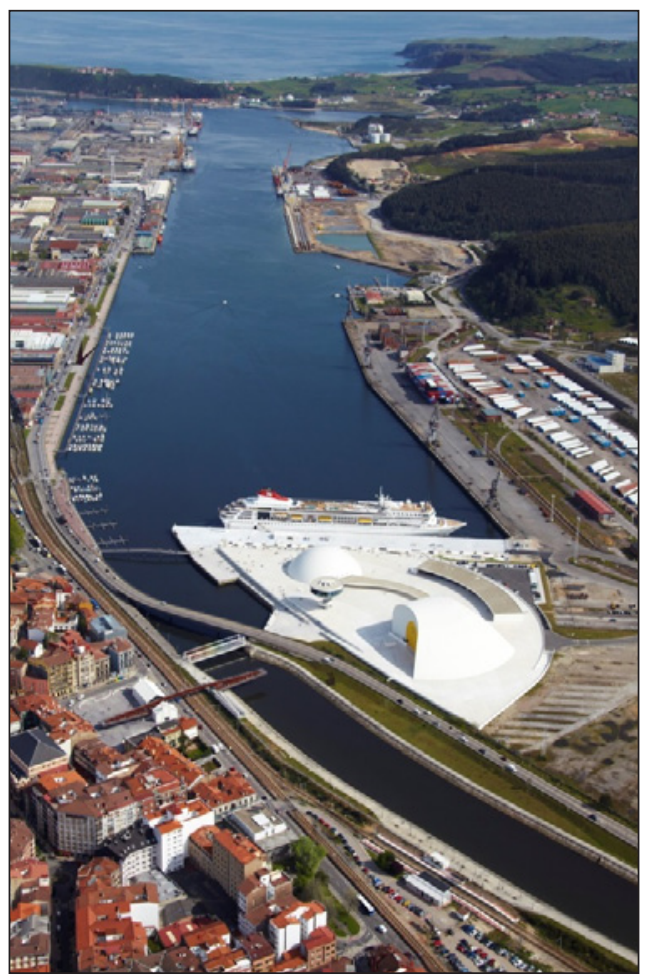

Fuente: Imagen cedida por el Ayuntamiento de Avilés y tomada en noviembre de 2013.

Además del Parque Empresarial y el Centro del Acero, la renovación de la ría y su entorno industrial está representada por la mejora de la Avenida del Conde de Guadalhorce, una arteria que recorre de norte a sur la margen izquierda de la ría, y que fue objeto entre 2005 y 2006 de una profunda transformación. Este antiguo y saturado eje industrial-portuario que había concentrado desde los primeros tiempos de la industrialización avilesina un importante número de empresas, así como algunos edificios industriales de interés arquitectónico y valor patrimonial (destacan las naves de los almacenes Balsera, de 1910) se dota de una nueva función que prima el uso ciudadano y toma la forma de un amplio paseo que mira a la ría, mejora la calidad general de la ría y refuerza la esencia urbana de esta orilla, dotada de equipamientos propios de un espacio con vocación de foco de recreo y disfrute ciudadano, además de dar paso al puerto y a las empresas que están instaladas en las áreas industriales aledañas (Figura 4). 


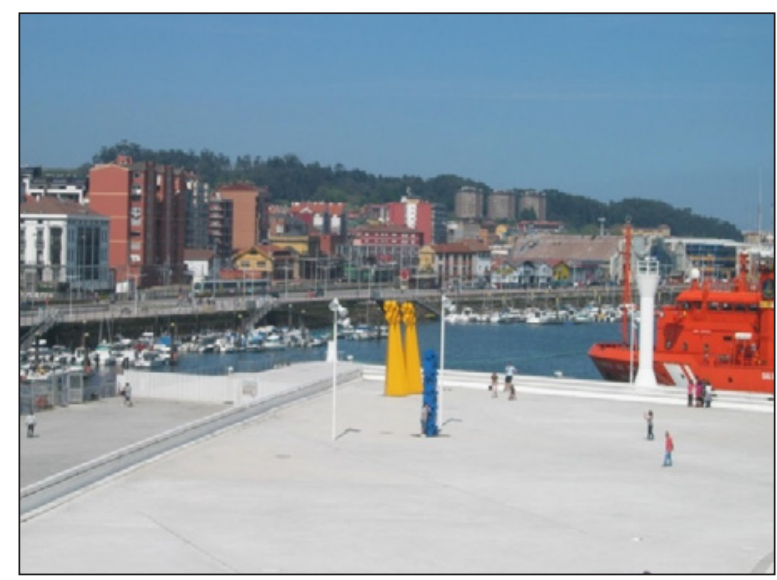

Fuente: Foto de la autora, abril de 2014.

Del conjunto de actuaciones previstas por el Ayuntamiento de Avilés para renovar la ría a partir de la herencia siderúrgica y su engarce con el desarrollo turístico y urbano, hay que destacar el proyecto de mayor impacto social y mediático: el Centro Cultural Niemeyer, situado junto a la dársena de San Agustín, en la zona de los antiguos muelles de Ensidesa (Figura 5). Esta propuesta representó un verdadero revulsivo para la ciudad, pues no solo implicaba alterar los usos del suelo y el paisaje heredado, sino que aportaba una función cultural inédita y una proyección exterior sin precedentes. El proyecto nació vinculado a la Fundación Príncipe de Asturias, que en el año 2005 lo recibió como regalo del arquitecto brasileño Óscar Niemeyer y que facilitó la relación entre el autor y el Gobierno del Principado, contactos que culminaron en un acuerdo sellado en marzo de 2006 para localizar el centro cultural en Avilés. La obra, única en España del brasileño, costó más de 40 millones de euros y se ejecutó entre 2008 y 2011. El 25 de marzo de 2011 se inauguró el nuevo espacio cultural compuesto por cinco edificios: el Auditorio, la Cúpula, la Torre-Mirador, el Edificio Polivalente y la Plaza Abierta, con un notable «efecto llamada» sobre los visitantes nacionales y extranjeros (vid. Tabla 2).

En los meses previos a su inauguración, medios de comunicación vascos saludaban así la llegada del Niemeyer: «En medio de una ría, castigada primero por la industrialización salvaje y después por la desindustrialización, emerge hoy un edificio que son en realidad cuatro y que promete con sus paredes de hormigón provocar el mismo efecto que hace ya casi 20 años causó el titanio en otra ría: la de Bilbao, gracias a otro arquitecto: Frank Gehry. Avilés se mira en el Guggenheim, pero, sobre todo, mira por primera vez de frente a su ría y, con ella, al turismo (...). Llegados al Niemeyer no hay que enfrentarse a colas ni a taquillas, porque el centro cultural, antes que una sala de exposiciones o un auditorio es una plaza pública en la que pueden convivir más de 15.000 personas sin miedo a pisarse» (http://www. elcorreo.com/vizcaya). 
Pero lo que debería haber sido el recurso clave de la proyección turística de Avilés al exterior (una suerte de segundo Guggenheim en el norte del país) se quebró parcialmente en 2012 por problemas de gestión financiera y política entre la Fundación responsable del Centro, el Gobierno del Principado de Asturias y el propio Ayuntamiento de Avilés; problemas que en términos prácticos se traducen en un redimensionamiento de las actividades y de las acciones de promoción y en severos recortes financieros. No obstante esta sombra en el proceso general de transformación de Avilés, la esencia de la estrategia local sigue vigente y, tal y como estudios recientes demuestran, la capacidad de respuesta de los agentes urbanos es elevada y «la red de actores que apoyaban al Ayuntamiento se ha mantenido muy unida» (Prada, 2014b: 200). PARAATRAQUE DE EMBARCACIONES TURÍSTICAS; AL OTRO LADO DE LA RIAA, EL CASCO URBANO DE AVILÉS

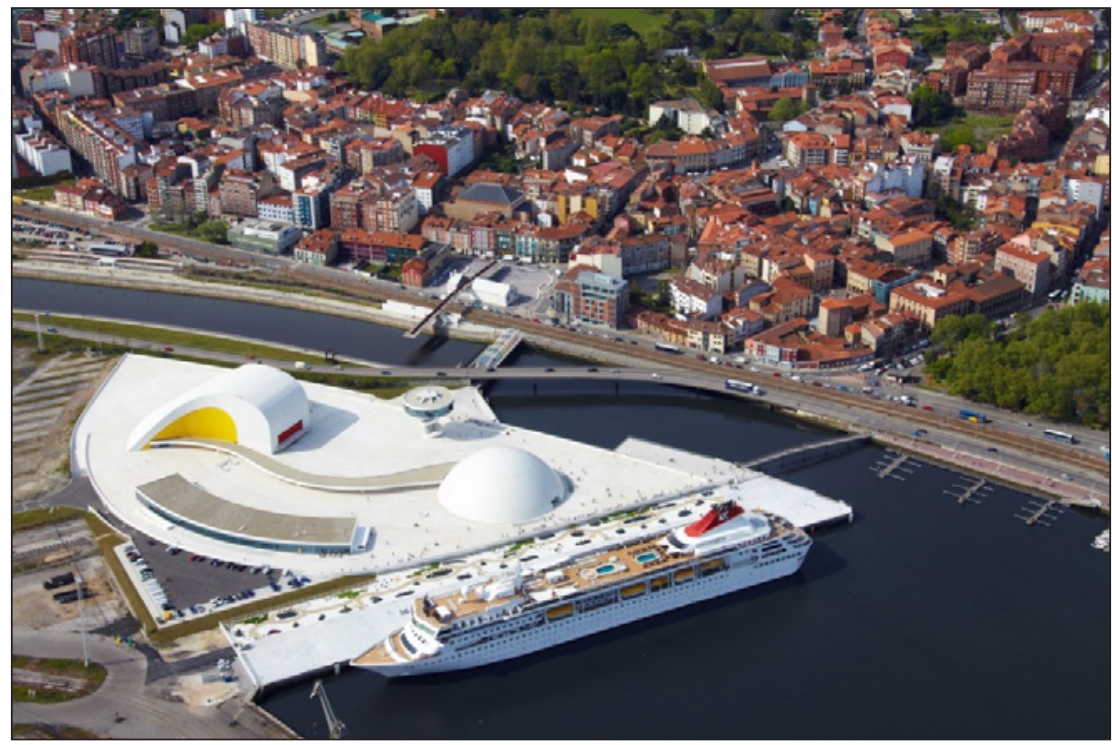

Fuente: Foto cedida por el Ayuntamiento de Avilés y tomada en noviembre de 2013.

\section{ENFOQUE, ALCANCE Y RECURSOS DE LA NUEVA FUNCIÓN TURÍSTICA AVILESINA}

Son abundantes los ejemplos de ciudades de tradición industrial que en Europa y en España mudan paulatinamente esta función productiva, basada con frecuencia en actividades de industria pesada y transformadora, por funciones de marcado sesgo terciario, con especial orientación hacia el aprovechamiento de recursos culturales, recreativos, gastronómicos o comerciales, lo que deriva en una nueva función turística que se beneficia del auge mundial de esta actividad y de los apoyos institucionales al sector. La ciudad se configura como un destino turístico con una oferta que tiende a especializarse en turismo cultural y que integra los componentes antes citados. A su vez, esta tendencia se acompaña de acciones de polí- 
tica urbanística y local que transforman profundamente la morfología urbana y dota a las ciudades de una proyección al exterior inédita, lo que permite fortalecer la base productiva urbana, reforzar el tejido empresarial, atraer y fijar población y crear empleo en sectores alternativos (vid. el informe sobre El turismo urbano y la cultura-La experiencia europea publicado en 2005 por la OMT y disponible en http://ciutatinvisible.org/images/Jornades/ Articles/Turismo_urbano_y_cultura_1_-R.pdf).

En este contexto hay que situar la apuesta de los agentes institucionales de Avilés por el turismo urbano cultural, función que se proyecta y planifica con una escala supraurbana y supramunicipal, dado el pequeño tamaño del municipio avilesino y el desbordamiento histórico de sus actividades e infraestructuras y recursos más importantes hacia los municipios vecinos, con los cuales forma un territorio relativamente homogéneo y lo suficientemente cohesionado como para compartir políticas y acciones estratégicas que requieren de la cooperación institucional para garantizar el éxito al conjunto comarcal, con Avilés como elemento tractor del turismo que se trata de impulsar.

\section{IV.1. Integración comarcal para sumar capacidades y mejorar resultados}

El municipio de Avilés está integrado en la Mancomunidad Comarca de Avilés, que tiene entre sus objetivos promocionar la comarca como destino turístico. En este marco, el programa de actuación de la Oficina de Turismo se desarrolla con una orientación de prestación informativa regional y promoción turística comarcal, lo que se complementa con acciones de difusión y promoción del territorio local. Avilés renovó en 2013 la Marca $Q$ de Calidad Turística otorgada por el Instituto para la Calidad Turística Española (ICTE) en el año 2007. Esta acreditación avala la adecuación del equipamiento y sistema de trabajo de a las normas y exigencias establecidas por las entidades públicas y privadas del sector en destinos turísticos consolidados (Ayuntamiento de Avilés, 2013).

Desde abril del 2006 la Oficina de Turismo de Avilés se ubica en la planta baja del Centro de Recepción Turismo Comarca Avilés, un edificio catalogado como bien histórico artístico y estratégicamente situado entre el Centro Niemeyer y la entrada al Casco Histórico, buscando el engarce entre los dos recursos clave de la ciudad y la conexión entre esta y la orilla opuesta de la ría.

El Centro en su conjunto alberga los servicios de atención informativa a turistas o visitantes y los programas de difusión y promoción del destino turístico. Complementariamente acoge la gerencia y sede social de la Mancomunidad Comarca Avilés, el despacho del coordinador de Programas Europeos y desde el año 2012 la delegación municipal de Festejos. En este mismo edificio se ubica la Oficina de Turismo, repartida en tres espacios con identidad funcional específica (Ayuntamiento de Avilés-Turismo, 2013):

- Espacio de atención informativa, con cuatro puestos de atención al público adaptados para acoger a personas con minusvalías.

- Espacio de gestión con dos puestos de organización administrativa y tratamiento documental. Todos los puestos cuentan con apoyo telefónico, informático y acceso a Internet.

- Dependencia para archivo de folletos y documentación turística, así como para la elaboración de envíos de información turística. 
La infraestructura de atención al turismo parece suficiente y ajustada al tamaño de la Mancomunidad turística que integran los municipios de Avilés, Castrillón, Corvera e Illas, un pequeño territorio de 157 kilómetros cuadrados de superficie y una población de casi 124.000 habitantes, siendo que Avilés representa el 70\% de ese volumen demográfico y concentra también la mayoría de los recursos ligados al patrimonio industrial que se trata de potenciar (Tabla 1).

Tabla 1

DATOS GENERALES DE LA MANCOMUNIDAD COMARCA DE AVILÉS, 2011

\begin{tabular}{|c|c|c|c|c|}
\hline Municipio & Superficie Km2 & Población & Densidad & Capital \\
\hline Avilés & 26,8 & 83.617 & 3.120 & Avilés \\
\hline Castrillón & 55,3 & 22.893 & 414 & Piedras Blancas \\
\hline Corvera & 46 & 16.236 & 353 & Nubledo \\
\hline Illas & 25,5 & 1.020 & 40 & La Callezuela \\
\hline Total & $\mathbf{1 5 7 , 3}$ & $\mathbf{1 2 3 . 7 6 6}$ & $\mathbf{7 8 7}$ & \\
\hline
\end{tabular}

Fuente: Elaboración propia con datos de SADEI.

Prueba de la decidida apuesta local por el turismo y la promoción de Avilés y comarca, que busca captar visitantes foráneos e internacionales, es la presencia y participación activa en las llamadas «Redes de promoción del destino». Según consta en la Memoria de Actividad Turística (Ayuntamiento de Avilés, 2013), esa red se compone de las siguientes entidades:

- Spain Convention Bureau. Entidad dependiente de la FEMP que aglutina a las ciudades con capacidad de organizar congresos y eventos, con el objeto de promocionar la ciudad en el mercado MICE de ámbito nacional e internacional.

- Red de ciudades de Asturias. El Ayuntamiento de Avilés también participa en esta red junto con Oviedo, Gijón, SRT, FADE y las Cámaras de comercio de la tres ciudades. Esta red tiene por objeto promocionar turísticamente Asturias y especialmente, sus ciudades en el mercado turístico nacional.

- Spain Cool Cities. Marca de promoción turística de la Red de Ciudades de la España Verde: Avilés, Gijón, Santander, San Sebastián y La Coruña. Fue creada en 2009 para la promoción conjunta en el mercado internacional del turismo urbano en el contexto de la España Verde, poniendo en relación los recursos homogéneos que le dan singularidad respecto a otros territorios turísticos nacionales: el ecosistema natural, la gastronomía, la oferta artística, el patrimonio histórico e industrial, la dimensión paseable de sus ciudades y la dotación de equipamientos culturales innovadores.

Los datos sobre la evolución del turismo en Avilés apuntan a una creciente importancia de esta actividad a partir sobre todo del año 2004, cuando se aplican las medidas de promoción acordadas por la Mancomunidad y el Ayuntamiento avilesino, que despliegan una estrategia en frentes diversos: nuevos recursos turísticos, mejora y ampliación de la oferta comercial y hotelera, mejora de la calidad ambiental de la ría y su entorno y campañas de difusión a través de los canales turísticos al uso. La tabla 2 refleja el crecimiento sostenidos 
de visitantes, que pasan de 24.145 en 2004 a 59.006 en 2011, para caer aunque a niveles de 2010 en 2012 e iniciar de nuevo la recuperación en 2013. El llamativo aumento de las visitas en 2011 está relacionado con la inauguración del Centro Cultural Niemeyer y los recursos que a tal efecto se movilizaron dentro y fuera de Asturias, incluidos países del entorno comunitario. Ese año pasaron por la Oficina de turismo de Avilés un total de 59.006 visitantes, es decir, 25.691 más que el año anterior, lo que representa un incremento de 43,4\% sin precedentes en el turismo comarcal (Gráfico 1).

Tabla 2

EVOLUCIÓN SEGÚN PROCEDENCIA DE USUARIOS PRESENCIALES EN LA OFICINA DE TURISMO DE AVILÉS, 2004-2013 (VALORES ABSOLUTOS)

\begin{tabular}{|c|c|c|c|c|c|c|c|c|}
\hline PROCEDENCIA & $\mathbf{2 0 0 4}$ & $\mathbf{2 0 0 6}$ & $\mathbf{2 0 0 8}$ & $\mathbf{2 0 0 9}$ & $\mathbf{2 0 1 0}$ & $\mathbf{2 0 1 1}$ & $\mathbf{2 0 1 2}$ & $\mathbf{2 0 1 3}$ \\
\hline Avilés & 12.450 & 10.251 & 8.840 & 6.464 & 5.634 & 7.562 & 4.891 & 4.542 \\
\hline Asturias & 1.402 & 1.024 & 1.570 & 1.555 & 1.261 & 2.528 & 1.142 & 1.180 \\
\hline España & 9.031 & 16.421 & 18.347 & 22.703 & 23.086 & 43.228 & 22.813 & 24.324 \\
\hline Internacional & 1.262 & 1.732 & 2.569 & 2.599 & 3.145 & 5.216 & 4.193 & 4.309 \\
\hline TOTAL & $\mathbf{2 4 . 1 4 5}$ & $\mathbf{2 9 . 4 2 8}$ & $\mathbf{3 1 . 3 2 6}$ & $\mathbf{3 3 . 5 4 4}$ & $\mathbf{3 3 . 3 1 5}$ & $\mathbf{5 9 . 0 0 6}$ & $\mathbf{3 3 . 3 0 5}$ & $\mathbf{3 4 . 7 1 7}$ \\
\hline
\end{tabular}

Fuente: Ayuntamiento de Avilés. Oficina de Turismo. Elaboración propia.

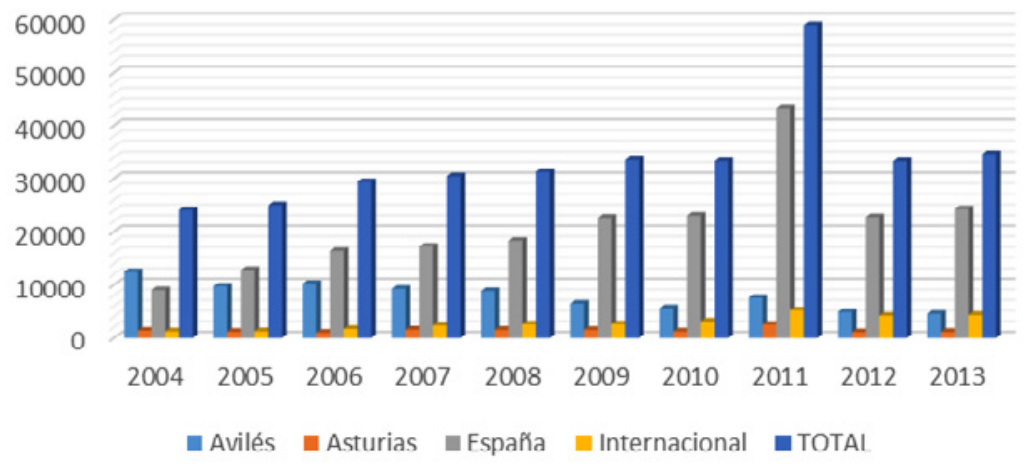

Fuente: Ayuntamiento de Avilés. Oficina de Turismo. Elaboración propia.

En este proceso de expansión del turismo tienen un peso destacado los visitantes procedentes de otras Comunidades Autónomas, el turismo nacional, que evoluciona de 13.516 visitantes en 2007 a 34.174 en 2011 y a 19.270 en 2013 por el motivo antes señalado del efecto Niemeyer. La procedencia de esos turistas apunta a un origen preferente: Madrid, seguido por regiones del norte peninsular: Cataluña, Castilla y León y País Vasco. También llegan visitantes de Andalucía y en menor medida de la Comunidad Valenciana y de Galicia (Tabla 3). 
Tabla 3

EVOLUCIÓN SEGÚN PROCEDENCIA DE LOS VISITANTES ESPAÑOLES, 2007-2013 (VALORES ABSOLUTOS)

\begin{tabular}{|l|c|c|c|c|c|c|c|}
\hline PROCEDENCIA & $\mathbf{2 0 0 7}$ & $\mathbf{2 0 0 8}$ & $\mathbf{2 0 0 9}$ & $\mathbf{2 0 1 0}$ & $\mathbf{2 0 1 1}$ & $\mathbf{2 0 1 2}$ & $\mathbf{2 0 1 3}$ \\
\hline Andalucía & 1.488 & 1.850 & 2.122 & 2.738 & 3.332 & 1.821 & 2.135 \\
\hline Madrid & 3.928 & 4.440 & 4.948 & 5.077 & 11.228 & 5.136 & 5.834 \\
\hline Cataluña & 2.247 & 2.409 & 3.119 & 2.856 & 5.049 & 2.838 & 2.925 \\
\hline Castilla y León & 1.982 & 1.376 & 1.541 & 2.122 & 4.938 & 2.537 & 2.740 \\
\hline Cast.- La Mancha & - & - & 1.569 & - & - & - & - \\
\hline Com. Valenciana & 2.020 & 1.687 & 1.920 & 1.981 & 2.529 & 1.366 & 1.807 \\
\hline Galicia & 914 & - & - & 1.250 & 2.878 & 1.676 & 1.688 \\
\hline País Vasco & 937 & 1.235 & 2.009 & 2.095 & 4.220 & 2.440 & 2.141 \\
\hline TOTAL & $\mathbf{1 3 . 5 1 6}$ & $\mathbf{1 . 2 9 9 7}$ & $\mathbf{1 7 . 2 2 8}$ & $\mathbf{1 8 . 1 1 9}$ & $\mathbf{3 4 . 1 7 4}$ & $\mathbf{1 7 . 8 1 4}$ & $\mathbf{1 9 . 2 7 0}$ \\
\hline
\end{tabular}

Fuente: Ayuntamiento de Avilés. Oficina de Turismo. Elaboración propia.

Tabla 4

EVOLUCIÓN DE LOS VISITANTES EXTRANJEROS POR PAÍS DE PROCEDENCIA, 2007-2013 (VALORES ABSOLUTOS)

\begin{tabular}{|c|c|c|c|c|c|c|c|}
\hline PAÍ́S & $\mathbf{2 0 0 7}$ & $\mathbf{2 0 0 8}$ & $\mathbf{2 0 0 9}$ & $\mathbf{2 0 1 0}$ & $\mathbf{2 0 1 1}$ & $\mathbf{2 0 1 2}$ & $\mathbf{2 0 1 3}$ \\
\hline Alemania & 312 & 307 & 345 & 328 & 655 & 678 & 585 \\
\hline Francia & 419 & 439 & 595 & 595 & 1.192 & 892 & 1053 \\
\hline Italia & 127 & 139 & 162 & 186 & 340 & 265 & 264 \\
\hline Portugal & 213 & 176 & 108 & 126 & 226 & 247 & 274 \\
\hline Reino Unido & 405 & 319 & 283 & 424 & 615 & 509 & 544 \\
\hline TOTAL & $\mathbf{1 . 4 7 6}$ & $\mathbf{1 . 3 8 0}$ & $\mathbf{1 . 4 9 3}$ & $\mathbf{1 . 6 5 9}$ & $\mathbf{3 0 2 8}$ & $\mathbf{2 . 5 9 1}$ & $\mathbf{2 . 7 2 0}$ \\
\hline
\end{tabular}

Fuente: Ayuntamiento de Avilés. Oficina de Turismo. Elaboración propia.

Si el foco se dirige hacia los visitantes extranjeros, los datos delatan una importancia menor de este tipo de turistas, aunque su número crece de año en año y si en 2007 eran 1.476 los que elegían Avilés como destino, en 2013 esa cifra se eleva a 2.720, con la excepción de nuevo reiterada del año 2011, que atrajo nada menos que a 3.028 visitantes internacionales, prueba del impacto de la campaña de difusión del Centro Niemeyer como motivo de su estreno y del «tirón» que representó este recurso en la actividad turística avilesina, frenado bruscamente al año siguiente por la crisis institucional antes comentada y pendiente de resolución (Tabla 4).

\section{IV.2. Hitos en la creación de la imagen turística avilesina}

Como se ha visto, el proyecto de un Avilés orientado hacia el turismo como actividad urbana estratégica forma parte de las políticas de diversificación económica y funcional del conjunto de la ría avilesina y su entorno, y se enmarca en el largo proceso de desindustrialización que tiene como hito fundamental el desmantelamiento de Ensidesa, cuyo cierre conlleva un cambio radical en la relación ciudad-industria y el fin de los muchos beneficios, 
y también inconvenientes (contaminación ambiental, saturación de tráfico pesado, imagen de ciudad negra, monocultivo industrial, etcétera), que se derivaron de la actividad siderúrgica durante cinco décadas.

Tabla 5

ACCIONES REACTIVADORAS DE AVILÉS Y SU ENTORNO HASTA 2006

\section{A) Refuerzo y modernización de la oferta comercial}

- Año 2000: Creación del Centro Comercial Parque Astur a las puertas de la ciudad, en Tabaza (Corvera).

- Año 2003: Se inaugura el Centro Comercial El Corte Inglés en el barrio de la Carriona. Nueva centralidad.

- Medidas de apoyo al pequeño comercio de proximidad.

B) Nuevos espacios productivos en suelo industrial obsoleto

- Se crea el Parque Empresarial Principado de Asturias en terrenos de Ensidesa (SepiInfoinvest). Superficie: 160 hectáreas (40 netas).

- Se pone en marcha el Centro Tecnológico del Acero (2005).

- El Ayuntamiento propone desarrollar un Centro Cultural y de Ocio en instalaciones siderúrgicas obsoletas. El arquitecto brasileño Oscar Niemeyer proyecta el nuevo complejo cultural (2006).

\section{C) Mejora de la oferta hotelera y modelo turístico competitivo}

- Nuevos hoteles de alto nivel: Hotel Villa de Avilés, de cuatro estrellas (Silken) y el Hotel Palacio de Ferrera, cinco estrellas, en un edificio histórico y céntrico (actualmente de la cadena NH Collection).

- Se crea la «Mancomunidad Turística Comarca de Avilés» con el objetivo de articular un modelo turístico competitivo.

Fuente: elaboración propia con datos del Ayuntamiento de Avilés (2002, 2004 y 2005).

Desde el inicio mismo del siglo XXI Avilés debe afrontar los problemas asociados a la herencia recibida y gestionar el legado territorial de la gran industria. La etapa de las acciones reactivadoras se inicia en 2000 y llega hasta 2006 y en ella el protagonismo corresponde a las autoridades locales, que actúan con los instrumentos a su alcance: planes estratégicos (Rodríguez y Busto, 2001) planes de dinamización económica y planeamiento urbanístico (Leira y Calvo, 2003; Benito del Pozo, 2004 y 2014; Prada 2014a-b) lo que da un balance de actuaciones ejecutadas y/o programadas que se refleja en la Tabla 5. Con posterioridad, en la etapa de 2007 a 2013, Avilés ha seguido mejorando la imagen urbana mediante acciones que van desde la peatonalización del casco histórico y la limpieza y remozamiento de fachadas hasta la recuperación de edificios singulares y la rehabilitación de puentes. Destaca en este sentido la intervención en el puente de San Sebastián (Figura 6), una obra de ingeniería heredada del siglo XIX y que se recupera, no sin controversia debido al estridente colorido que reemplaza al óxido acumulado con los años, para reforzar la conexión de las dos orillas de la ría y potenciar el Centro Niemeyer, que queda unido al Casco Histórico (y viceversa), pasando por delante de la Oficina de Turismo, reubicada en este punto estratégico de convergencia de recursos turísticos de la ciudad (Figura 7). 


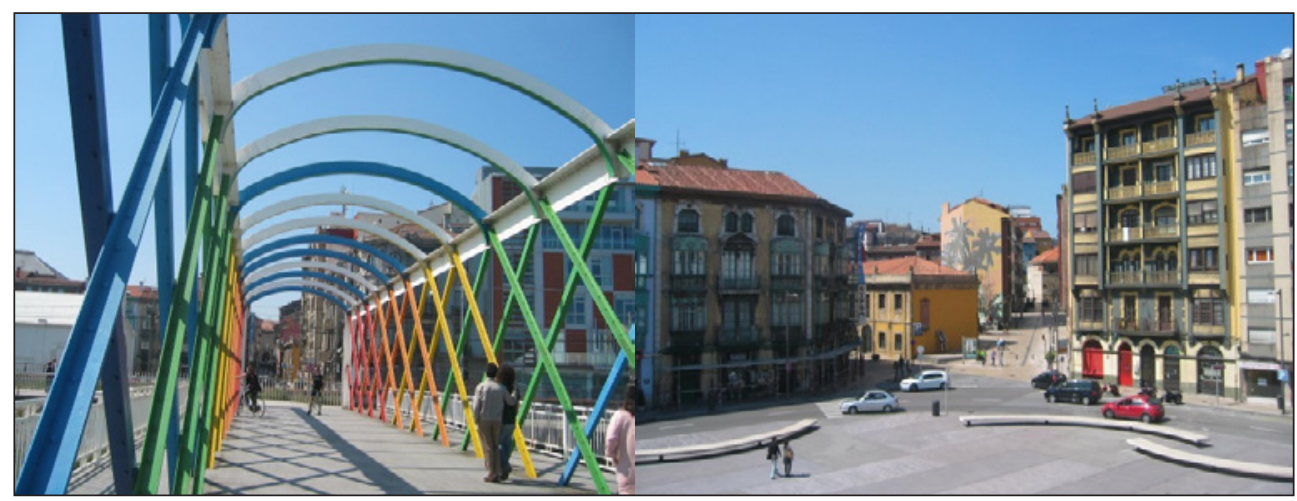

Fuente: fotografías de la autora tomadas en abril de 2014.

También los paseos se convierten en una prioridad desde 2007. Así la acción municipal reforma la antes referida Avenida de Guadalhorce, que da acceso al puerto deportivo; crea un paseo de la siderurgia que arranca de los antiguos muelles de Ensidesa y bordea, pegado al río, el antiguo recinto fabril, exhibiendo piezas industriales reinterpretadas como esculturas, lo que se traduce en un cambio radical del paisaje de la ría, apreciable de forma panorámica en las Figuras 3 y 5.

La vertiente comarcal de la estrategia avilesina se aprecia con claridad en la acción que ejecuta el municipio de Castrillón: recuperar como senda la zona del Espartal, un espacio costero revegetado por la desaparecida Real Compañía Asturiana de Minas, que discurre entre San Juan de Nieva y la playa de Salinas, en uno de cuyos extremos se alza desde 1993 el Museo de Anclas, al aire libre. Muy cerca de Salinas se localiza el Museo de la Mina de Arnao, un Bien de Interés Cultural que se suma desde 2013 al patrimonio industrial recuperado de la comarca. La prensa regional destacaba así lo que este recurso aporta y representa en términos turísticos: «La mina se abrió al público el 30 de julio y se cerró el 29 de diciembre. En esos meses visitaron el museo casi 7.000 personas (...). La rehabilitación del castillete y la mina de Arnao supuso una inversión de cinco millones de euros de los que 3,5 fueron aportados por la Unión Europea a través de los fondos FEDER y el resto por el Ayuntamiento de Castrillón. Las obras se prolongaron durante más de un año, pero las visitas turísticas tardaron en programarse. La empresa Sadim ejecutó también a finales del año pasado la rehabilitación de un tramo de 25 metros de galería que se sumó a las 100 rehabilitados inicialmente. Esas obras costaron 45.000 euros al Ayuntamiento» (http://www.lne.es/ aviles/2014/02/27/museo-mina-arnao) (vid. Laine, 2010).

En definitiva, Avilés y su entorno más inmediato (los municipios limítrofes agrupados bajo un mismo sello o imagen de marca) se han dotado de infraestructuras y recursos para reforzar la función turística del espacio vertebrado por la ría. Esto es el resultado de un conjunto de acciones estratégicas apoyadas al unísono por los gestores locales de los diferentes 
municipios, que trabajan de forma muy colaborativa en la misma dirección, con planes de calidad de la hostelería y del pequeño comercio especializado y con acciones complementarias de promoción de fiestas locales y participación ciudadana (carnavales, procesiones de Semana Santa), dentro de un esquema de marketing urbano que es común a numerosas ciudades postindustriales y como respuesta, según algunos autores, al shock que la ciudad padeció a causa de la quiebra del industrialismo (Prada, 2014b).

\section{CONCLUSIONES}

Avilés y su ría son un claro exponente de la transformación radical de un territorio sujeto durante décadas a la lógica y los impactos del industrialismo, que engendró una ciudadempresa de contaminado perfil y una economía urbana de monocultivo siderúrgico. Como se ha demostrado, Avilés ha sido capaz, sin renunciar a su pasado industrial, de regenerar el tejido productivo tras el cierre de su empresa motora, de crear una imagen de espacio limpio y de bienestar, de redefinir su urbanismo y de posicionarse como un espacio turístico con identidad propia. Esta experiencia, que remite a ejemplos similares en otras zonas del norte peninsular y que se inspira en modelos como Ría Bilbao 2000, debe su éxito a una estrategia de política urbanística que pone el foco en el aprovechamiento de los terrenos industriales abandonados, en la descontaminación ambiental y la regeneración del puerto y en la mejora del casco histórico, así como en una política turística de escala supramunicipal que se basa en la colaboración de las distintas corporaciones locales de la comarca avilesina para alcanzar, sumando recursos e infraestructuras, un tamaño de polo turístico más competitivo y diversificado, con oferta de elementos variados y singulares, entre los que destaca el Centro Cultural Niemeyer y el paisaje industrial en el que se enmarca.

Los resultados del conjunto de acciones e intervenciones analizadas demuestran que el turismo comarcal crece y que la ciudad y la ría han reforzado su atractivo turístico. En este proceso hay, no obstante, algunas sombras: los problemas de gestión y financiación que desde 2012 atenazan a los responsables del Centro Cultural Niemeyer y que han impedido que Avilés se consolide como destino internacional, aspiración que en 2006 parecía más que plausible. Hoy se trabaja con un horizonte más modesto, pero el gran cambio ya es una realidad y Avilés se perfila como un modelo urbano de transformación planificada exitosa en muchos aspectos, mostrando capacidad para revitalizarse y generar actividades alternativas que impulsen el crecimiento y un nuevo bienestar ciudadano.

\section{BIBLIOGRAFÍA}

ÁlVAREZ, M.A. (Ed.) (2003): Rutas Culturales y Turísticas de Patrimonio Industrial, Colección «Los Ojos de la Memoria». Gijón, Incuna.

ÁLVAREZ, M.A. (2007): Arqueología Industrial. El pasado por venir. Gijón: CICEES, Colección La Herencia Recuperada.

ÁlVAREZ, M.A. (Ed.) (2008): Del hierro al acero. Forjando la historia del patrimonio industrial metalúrgico, Colección «Los Ojos de la Memoria». Gijón, Incuna.

ÁlVAREZ, M.A. (Ed.) (2010): Patrimonio industrial y paisaje. Gijón, TICCIH EspañaCICEES, Gijón. 
AYUNTAMIENTO DE AVILÉS (2002a): Avance Plan General de Ordenación Urbana de Avilés. Avilés.

AYUNTAMIENTO DE AVILÉS (2002b): Avance Plan Especial de Protección y Mejora del Patrimonio. Avilés.

AYUNTAMIENTO DE AVILÉS (2004): Proyecto REVITA. Diagnóstico y estrategias de revitalización en las áreas industriales de Avilés (inédito). Avilés.

AYUNTAMIENTO DE AVILÉS (2005): Plan General de Ordenación Urbana de Avilés. Avilés.

AYUNTAMIENTO DE AVILÉS (2013): Turismo-Memoria de Actividad 2013. Avilés.

BENITO DEL POZO, P. (2004): «Discursos, propuestas y acciones sobre la ciudad postindustrial». Anales de Geografía de la Universidad Complutense, n $24,9-29$.

BENITO DEL POZO, P. (2012): «Territorio, paisaje y herencia industrial. Debates y acciones en el contexto europeo». Documents d'Anàlisis Geogràfica, n ${ }^{\circ}$ 58/3, 443-457.

BENITO, P. y PIÑEIRA, M.J. (2014): «Industry and Urban Heritage» in N. Kotze; R. Donaldson; G. Visser (Ed.): Life in a Changing Urban Landscape. Johannesburg, University of Johannesburg, 149-158.

BIEL, P. y CUETO, G. (Coords.) (2011): 100 elementos del patrimonio industrial en España. Zaragoza, Ticcih-España, CICEES e Instituto del Patrimonio Cultural de España.

CAÑIZARES, M.C. (2010): «El patrimonio industrial: un recurso del territorio y un componente del paisaje» en V Congreso TICCIH-España. Patrimonio Industrial y Paisaje. Gijón, TICCIH, 497-506.

CAPEL, H. (1996): «La rehabilitación y el uso del patrimonio histórico industrial». Documents d Anàlisi Geogràfica, nº 29, 19-50.

COMARCA DE AVILÉS (varios años): Plan de Dinamización Turística. Avilés. Ayuntamiento de Avilés.

CUESTA ÁLVAREZ, Á. (2006): «La reconversión de la siderurgia integral española. Un modelo exportable». Técnica Industrial, $\mathrm{n}^{\circ}$ 263, 40-46.

DE LA MADRID, J.C. (2008): Avilés, una historia de mil años. Avilés, Azucel.

ERICE, F. (1980): La burguesía industrial asturiana. Gijón, Silverio Cañada.

GÓMEZ GARCÍA, M.V. (2007): La metamorfosis de la ciudad industrial. Madrid, Talasa Ediciones.

HOEHMANN, R. (2008): «El patrimonio industrial del hierro y el acero en la Europa moderna. Preservación antes que la extinción» en Del hierro al acero (Álvarez, M.A., coord.). Gijón, Incuna, 17-26.

JUARISTI, J. (2012): «Algunas reflexiones sobre la revitalización y regeneración urbana en Asturias Central y en Bilbao Metropolitano (1980-2010)» en El impacto del modelo autonómico en las ciudades españolas. Una aproximación interdisciplinar (Valenzuela, M., Coord.). Madrid, UAM Ediciones, 467-515.

LAINE, G. (2010): «Arnao: la singularidad de un territorio a partir de su patrimonio industrial» en Patrimonio industrial y paisaje. TICCIH España-CICEES, Gijón, 409-416.

LEIRA, E. y CALVO, L. (2003): «Avilés ante un nuevo futuro». Ciudades: Revista del Instituto Universitario de Urbanística de la Universidad de Valladolid, $\mathrm{n}^{\mathrm{0}}$ 7, 103-128.

LÓPEZ TRIGAL, L.; RELEA, C. y SOMOZA, J. (2003): La ciudad. Nuevos procesos, nuevas respuestas. León, Secretariado de Publicaciones de la Universidad de León. 
LÓPEZ TRIGAL, L. (Dir.) (2015): Diccionario de Geografía Aplicada y Profesional. León, Área de Publicaciones de la Universidad de León.

MANERO, F.; MOLINA, I. (2014): «Estrategias territoriales ante la crisis: cultura del territorio y calidad institucional» en Geografía de la crisis económica en España (Albertos, J.M. y Sánchez, J.L.). Valencia, PUV Universitat de Valencia, 39-74.

MÉNDEZ, R. (Ed.) (2010): Estrategias de innovación industrial y desarrollo económico en las ciudades intermedias de España. Madrid, Fundación BBVA.

MÉNDEZ, R. (2012): «Ciudades y metáforas. Sobre el concepto de resiliencia». Ciudad y Territorio. Estudios Territoriales, $\mathrm{n}^{\circ} 172,215-231$.

MÉNDEZ, R. y PASCUAL, H. (Eds.) (2006): Industria y ciudad en España: Nuevas realidades, nuevos retos, Madrid, Thomson-Civitas,

MORALES, G. (1982): Industria y espacio urbano en Avilés. Gijón, Silverio Cañada (2 vols.). OJEDA, G. (1985): Asturias en la industrialización española, 1833-1907. Madrid, Siglo XXI.

PARDO ABAD, C.J. (2008): Turismo y patrimonio industrial. Madrid, Síntesis.

PARDO ABAD, C.J. (2010): «El patrimonio industrial en España: análisis turístico y significado territorial de algunos proyectos de recuperación. Boletín de la Asociación de Geógrafos Españoles, n' 53, 239-264.

PRADA TRIGO, J. (2014a): «Declive urbano, estrategias de revitalización y redes de actores. El peso de las trayectorias locales a través de los casos de estudio de Langreo y Avilés (España)». Revista de Geografía Norte Grande, $\mathrm{n}^{\circ}$ 57, 33-51.

PRADA TRIGO, J. (2014b): Avilés. Una ciudad entre dos crisis: actores locales y estrategias de revitalización. Avilés, Azucel.

RODRÍGUEZ, J.M. y BUSTO, R.D. (2001): «La transformación de un paisaje tradicional industrial. El plan estratégico de Avilés» en Actas XII Congreso de Geógrafos Españoles. Oviedo, AGE y Universidad de Oviedo, 461-465.

RODRÍGUEZ, F. y MENÉNDEZ, R. (2005): Geografía de Asturias. Barcelona, Ariel.

SÁNCHEZ, S.; MÉNDEZ, R. y PRADA, J. (2012): «Avilés, entre el declive y la revitalización: ¿en la génesis de un nuevo modelo de desarrollo?». Boletín de la Asociación de Geógrafos Españoles, $\mathrm{n}^{\circ}$ 60, 327-353.

TOMÉ, S. (2007): «Avilés (Asturias): la morfología parcelaria, patrimonio cultural y sostenibilidad». En I Congreso de Estudios Asturianos, Real Instituto de Estudios Asturianos, Oviedo, 167-185.

TOMÉ, S. (2010): «Langreo, Mieres, Ponferrada, Puertollano: cambios funcionales y morfológicos en ciudades minero industriales». Scripta Nova, vol. XIV, 336 (20 de septiembre de 2010), disponible en: http://www.ub.edu/geocrit/sn/sn-336.htm

TROITIÑO, M.A. y otros (Coords.) (2008): Destinos turísticos: viejos problemas, ¿nuevas soluciones? Colección Estudios, $\mathrm{n}^{\circ}$ 121. Cuenca. Ediciones de la Universidad de CastillaLa Mancha.

UNIVERSITY OF BIRMINGHAM (2013): Conference Proceedings. Rust, Regeneration an Romance. Iron and Steel Landscapes and Cultures. Birrmingham, Ironbridge International Institute for Cultural Heritage. 